nine to 14 years than less active boys. The effects of MVPA and VPA in girls tended to be protective but were not significant. These findings may reflect gender differences in choice of active pursuits and will be the subject of future analyses.

\section{RF34 PARENT AND CHILD MISPERCEPTION OF CHILD WEIGHT STATUS: A CROSS-SECTIONAL ANALYSIS OF THE CORK CHILDREN'S LIFESTYLE STUDY (CCLAS)}

${ }^{1}$ E Kelleher, 'S Millar*, ${ }^{1,2}{ }^{2}$ Shiely, ${ }^{1} \mathrm{IJ}$ Perry, ${ }^{1} \mathrm{JM}$ Harrington. 'SChool of Public Health, University College Cork, Cork, Ireland; ${ }^{2}$ HRB Clinical Research Facility, Mercy University Hospital, Cork, Ireland

\subsection{6/jech-2018-SSMabstracts.122}

Background Despite the increased global awareness of childhood obesity, a high proportion of parents and children continue to misclassify child weight status. The aim of this study was to determine parent and child misperception of child weight and identify the determinants influencing this misperception.

Methods A cross-sectional study involving 1075 children, aged 8-11 years, drawn from primary schools in Cork city and county in Ireland. Data were collected using child and parent self-administered questionnaires. Physical measurements were taken by trained researchers according to standard procedures. Univariate and multivariable logistic regression analysis was used to examine factors influencing parental and child perceptions regarding child weight.

Results Almost one-quarter of parents of all children misclassified their child's weight status. Forty four per cent of parents of overweight or obese children underestimated their child's weight. In all children, factors associated with parental misperception of child weight included the child being female $(\mathrm{OR}=1.95 ; 95 \% \mathrm{CI} 1.36$ to $2.81, \mathrm{p}<0.001)$, being overweight or obese $(\mathrm{OR}=2.84 ; 95 \% \mathrm{CI} 1.95$ to $4.15, \mathrm{p}<0.001)$, child misclassification of own weight $(\mathrm{OR}=3.28$; 95\% CI 2.26 to 4.78, $\mathrm{p}<0.001)$ and parent reported child computer use $(\mathrm{OR}=1.64 ; 95 \% \mathrm{CI} 1.12$ to $2.39, \mathrm{p}=0.01)$. In overweight or obese children, accuracy in parental perception of weight improved with increasing child age $(\mathrm{OR}=0.49$; 95\% CI 0.27 to $0.88, \mathrm{p}=0.02)$. Of children who were overweight/obese, $76 \%(n=213)$ underestimated their weight. These children had increased odds of misperceiving their own weight status if their parents misclassified their child's weight $(\mathrm{OR}=3.98$; 95\% CI 1.95 to $8.10, \mathrm{p}<0.001)$.

Conclusion Findings suggest that in an obesogenic society, where overweight and obesity has become the norm, the capacity of both parents and children to correctly classify child weight status is significantly impaired. Health care professionals should be aware of the frequent misperception of weight status, especially when dealing with parents of younger children and children who are overweight or obese.

\section{RF35 EXAMINING ASSOCIATIONS BETWEEN ETHNIC DENSITY AND PHYSICAL ACTIVITY IN ADOLESCENTS: EVIDENCE FROM THE ORIEL STUDY}

N Berger*, D Lewis, S Cummins. Department of Public Health, Environments and Society, London School of Hygiene and Tropical Medicine, London, UK

10.1136/jech-2018-SSMabstracts.123
Background Most adolescents do not achieve the recommended level of physical activity (PA) in the UK. The ethnic density hypothesis suggests that living in areas with higher proportions of people of the same ethnicity may confer health benefits. We explore whether school and neighbourhood ethnic densities are associated with adolescent utilitarian and leisure physical activity behaviours and whether these effects contribute to explaining ethnic differences in these behaviours.

Methods We used longitudinal data from the Olympic Regeneration in East London (ORiEL) study. In 2012, 3088 adolescents aged 11-12 were recruited from 25 schools in four deprived and ethnically diverse boroughs of East London. Adolescents were followed-up in 2013 and 2014. Own-group ethnic density was operationalised at school- and neighbourhood-levels in 2012/14 and 2011 respectively, and calculated as the percentage of adolescents, in the relevant school or neighbourhood (defined as 'lower layer super output area' of their home-address), who were of the same ethnic group. Analyses were restricted to White UK, White Mixed, Black African and Bangladeshi groups. The outcomes were selfreported binary variables: walking to school, walking for leisure, and outdoor PA. We identified potential confounders. We estimated logistic regression models with generalised estimating equations for each outcome and included interaction terms between ethnicity and ethnic densities. Item nonresponse was handled using multilevel multiple imputation. Final sample size was 1160 adolescents.

Results At school-level, there was consistent evidence that ethnic density amplifies ethnic differences in walking to school. For each 10 percentage point increase in ethnic density, there was evidence of increased probability of walking to school in Bangladeshi adolescents (OR=1.20; 95\% CI 1.09 to 1.31$)$ and decreased probability of walking to school in Black African $(\mathrm{OR}=0.58 ; 95 \% \mathrm{CI} 0.45$ to 0.75$)$ and White Mixed adolescents $(\mathrm{OR}=0.51 ; 95 \% \mathrm{CI} 0.35$ to 0.76$)$, after adjusting for confounders. Associations with walking for leisure and outdoor PA were in expected directions but not consistently observed in all ethnic groups.

At neighbourhood-level, evidence was more restricted. Amplification of ethnic differences was found for walking to school in Bangladeshi adolescents $(\mathrm{OR}=1.31 ; 95 \%$ CI 1.14 to 1.51) and for outdoor PA in White UK adolescents $(\mathrm{OR}=0.85 ; 95 \%$ CI 0.76 to 0.94$)$.

Conclusion These results suggest that ethnic density contributes to explaining differences in PA by amplifying ethnic differences in some forms of PA. Further research is needed to confirm these results in different populations and for different health behaviours.

\section{RF36 A CROSS-COUNTRY COMPARISON OF SELF-REPORTED EXPOSURE TO SUGARY DRINK MARKETING AND SUGAR-SWEETENED BEVERAGE INTAKE}

${ }^{1} \mathrm{H}$ Forde*, ${ }^{1} \mathrm{~J}$ Adams, ${ }^{1} \mathrm{M}$ White, ${ }^{2} \mathrm{~L}$ Levy, ${ }^{2} \mathrm{~F}$ Greaves. ${ }^{1} \mathrm{CEDAR}$, MRC Epidemiology Unit, University of Cambridge, Cambridge, UK; ${ }^{2}$ Public Health England, London, UK

\subsection{6/jech-2018-SSMabstracts. 124}

Background High sugar consumption contributes to the global obesity epidemic. Sugar-sweetened beverages (SSBs) constitute a significant proportion of sugar consumption and are independently associated with non-communicable diseases. Some 